\title{
A Phase 1 Study of Bortezomib and Romidepsin in Patients with Chronic Lymphocytic Leukemia/Small Lymphocytic Lymphoma, Indolent B-Cell Lymphoma, Peripheral T-Cell Lymphoma, or Cutaneous T-Cell Lymphoma
}

\author{
Beata Holkova $^{1,2}$, Victor Yazbeck ${ }^{1,2}$, Maciej Kmieciak ${ }^{1}$, Prithviraj Bose ${ }^{1}$, Shuo Ma $^{3}$, Amy \\ Kimball $^{4}$, Mary Beth Tombes ${ }^{1}$, Ellen Shrader ${ }^{1}$, Wen Wan ${ }^{5}$, Caryn Weir-Wiggins ${ }^{1}$, Amanda \\ Singh $^{1}$, Kevin T. Hogan ${ }^{1}$, Sarah Conine ${ }^{1}$, Heidi Sankala ${ }^{1}$, John D. Roberts ${ }^{1}$, Thomas C. \\ Shea $^{6}$, and Steven Grant ${ }^{1,2,7,8,9}$ \\ ${ }^{1}$ Massey Cancer Center, Virginia Commonwealth University, Richmond, VA, USA \\ ${ }^{2}$ Department of Internal Medicine, Virginia Commonwealth University, Richmond, VA, USA \\ ${ }^{3}$ Robert H. Lurie Comprehensive Cancer Center, Northwestern University, Chicago, IL, USA \\ ${ }^{4}$ Marlene and Stewart Greenebaum Cancer Center, University of Maryland, Baltimore, MD, USA \\ ${ }^{5}$ Department of Statistics, Virginia Commonwealth University, Richmond, VA, USA \\ ${ }^{6}$ Lineberger Comprehensive Cancer Center, University of North Carolina, Chapel Hill, NC, USA \\ ${ }^{7}$ Department of Microbiology and Immunology, Virginia Commonwealth University, Richmond, VA, \\ USA \\ ${ }^{8}$ Department of Biochemistry and Molecular Biology, Virginia Commonwealth University, \\ Richmond, VA, USA \\ ${ }^{9}$ The Institute for Molecular Medicine, Virginia Commonwealth University, Richmond, VA, USA
}

\begin{abstract}
A phase 1 study was conducted to determine the dose-limiting toxicities and maximum tolerated dose (MTD) for bortezomib followed by romidepsin on days 1, 8, and 15 in patients with relapsed/ refractory CLL/SLL or B- or T-cell lymphoma. Eighteen treated patients were evaluable for response. The MTD was $1.3 \mathrm{mg} / \mathrm{m}^{2}$ bortezomib and $10 \mathrm{mg} / \mathrm{m}^{2}$ romidepsin; median treatment duration was 3 cycles at this dose. The dose-limiting toxicities were grade 3 fatigue, vomiting, and chills. Two patients had partial responses, one lasting $>2$ years, 8 had stable disease, and 8 had progressive disease. The median duration of stable disease was 3.5 cycles. Correlative studies examining expression of NF- $\mathrm{BB}, \mathrm{XIAP}, \mathrm{Bcl-xL}$, and Bim yielded variable results. The safety
\end{abstract}

Corresponding Author: Beata Holkova, Virginia Commonwealth University, PO Box 980070, Richmond, VA 23298-0070. Phone: 804-628-2581; Fax: 804-628-5920; beata.holkova@ vcuhealth.org.

Current affiliations: P. Bose: MD Anderson Cancer Center, Houston, TX, USA; J.D. Roberts: Yale University, New Haven, CT, USA; A. Kimball: Amgen, Inc.

Disclosure of Potential Conflicts of Interest:

No potential conflicts of interest were disclosed. Disclosure forms provided by the authors are available with the full text of this article at www.informahealthcare.com/lal. 
profile was consistent with that reported for single-agent bortezomib and romidepsin. This regimen has modest activity in heavily pre-treated patients with relapsed/refractory CLL or B- or T-cell lymphoma. NCT00963274.

\section{Keywords}

Bortezomib; romidepsin; phase 1 clinical trial; lymphoma

\section{Introduction}

Non-Hodgkin lymphoma (NHL) is a heterogeneous disease that arises from malignant B, T, and NK cells [1]. The incidence rate of NHL has increased over the last 3 decades [2]. Chronic lymphocytic leukemia (CLL) is the most prevalent adult leukemia and remains incurable with current therapy, except with allogeneic bone marrow transplant, which is associated with a high risk of morbidity and mortality. Patients with recurrent disease generally have a poor outcome and novel therapies are needed. Given that the depth of responses such as complete response (CR) rate or minimal residual disease negativity tend to correlate with improved clinical outcomes [3], rationally designed combination strategies with targeted therapies offer the potential to increase clinical benefit with a toxicity profile that is relatively well tolerated.

The proteasome, a multisubunit protease complex responsible for the degradation of cellular proteins, has been targeted by anticancer therapeutics. Although the proteasome is ubiquitously expressed in all cell types, cancer cells are more sensitive than normal cells to proteasome inhibitors [4]. Proteasome inhibitors induce apoptosis through multiple mechanisms, including inactivating NF- $\kappa \mathrm{B}$, activating the c-Jun N-terminal kinase pathway, and activating Bcl-2 family proteins. The clinical activity of proteasome inhibitors was first demonstrated with bortezomib in the treatment of refractory hematologic malignancies [5]. Bortezomib is thought to act through inhibition of the NK- $\kappa$ B pathway, although some evidence argues that it may have the opposite effect [6]. Bortezomib is currently approved in mantle cell lymphoma [7] and has shown clinical activity in several NHLs [8].

Histone deacetylases (HDACs) have also been targeted as anticancer therapeutics [9]. Histone deacetylation promotes chromatin condensation and represses gene expression. The functions of a variety of proteins involved in cell proliferation, gene expression, and cell death are controlled by lysine residue acetylation. HDAC inhibitors (HDACIs) promote the acetylation of lysine residues, which alters both transcription-dependent and transcriptionindependent cellular pathways. Romidepsin is an HDACI approved for patients with relapsed peripheral T-cell lymphoma (PTCL) [10] and cutaneous T-cell lymphoma (CTCL) [11-13] who have received at least one prior systemic therapy. In a pivotal trial, single-agent romidepsin induced an overall response rate and CR rate of 26\% and 15\% in PTCL [14], and $34 \%$ and $6 \%$ in CTCL [12]. Given the modest activity of romidepsin, combinations with other drugs have been studied, including with targeted agents such as bortezomib, in several hematological malignancies. One such study incorporating romidepsin, bortezomib, and dexamethasone was initiated in patients with relapsed/refractory multiple myeloma and 
showed durable responses with a median time to progression of 7.2 months and median overall survival of greater than 3 years [15].

Mechanistically, HDACIs activate the prosurvival NF- $\mathrm{kB}$ pathway, which consequently limits HDACI therapeutic activity. We and multiple other groups have demonstrated marked in vitro synergistic interactions between bortezomib and a variety of different HDACIs in leukemia cells [16] and multiple myeloma cells [17]. Multiple mechanisms have been postulated to underlie this interaction, including proteotoxic stress and disruption of aggresome formation, among others [18]. Exposure to sublethal concentrations of romidepsin and bortezomib administered at low concentrations ( $\sim 3$ to $5 \mathrm{nM}$ ) were shown to induce synergistic cell death in CLL cells [19]. At the molecular level, bortezomib prevented romidepsin-induced NF- $\kappa B$ activation and downregulation of the canonical NF- $\kappa B$ pathway, as reflected by diminished expression of RelA and the NF- $\kappa \mathrm{B}-$ dependent survival proteins $\mathrm{Bcl}-\mathrm{xL}$ and XIAP. The combination downregulated alternative pathway NF- $\mathrm{\kappa B}$ signaling, as reflected by diminished expression of p100 to $\mathrm{p} 52$, and increased expression of the proapoptotic protein Bim, resulting in caspase activation. Based on these encouraging preclinical results in CLL [19], a phase 1 clinical trial of bortezomib in combination with romidepsin was initiated for patients with relapsed/refractory CLL and small lymphocytic lymphoma (SLL). Following approval of romidepsin for relapsed/refractory PTCL [10] and CTCL $[12,13]$ and reports of single-agent activity of bortezomib in CTCL [20], the study was expanded to include patients with these diseases. Finally, patients with indolent B-cell lymphoma, where both HDACIs and proteasome inhibitors have modest single-agent activity [21], were included in this clinical trial.

\section{Materials and Methods}

\section{Patient eligibility}

Eligible patients were at least 18 years old, with an Eastern Cooperative Oncology Group performance status of 0 or 1, and a diagnosis of relapsed or refractory CLL/SLL, indolent Bcell lymphoma (including FL, marginal zone B-cell lymphoma, and lymphoplasmacytic lymphoma), PTCL (including anaplastic large cell lymphoma [ALK positive or negative], angioimmunoblastic T-cell lymphoma, enteropathy-associated T-cell lymphoma, extranodal NK/T-cell lymphoma [nasal type], hepatosplenic T-cell lymphoma, PTCL not otherwise specified, and subcutaneous panniculitis-like T-cell lymphoma), or CTCL (with subtypes of mycosis fungoides Stage IB or higher, Sézary syndrome, or primary cutaneous anaplastic large cell lymphoma with failure on a previous systemic treatment). Patients with mantle cell lymphoma were not included in this study due to competing studies with ibrutinib. Prior allogeneic stem cell transplant was allowed provided that at least 6 months had elapsed since allogeneic transplant, no graft-versus-host disease was present, and no immunosuppressive therapy was currently being administered. Additional eligibility criteria included normal to near-normal kidney (serum creatinine $\leq 1.2 \mathrm{mg} / \mathrm{dL}$ or actual or calculated creatinine clearance $\geq 60 \mathrm{~mL} / \mathrm{min}$ ) and liver (AST, ALT $\leq 2.5 \times$ upper limit of normal; bilirubin $\leq$ $\mathrm{ULN}$ ) function, absolute neutrophil count greater than $1.5 \times 10^{9} / \mathrm{L}$, hemoglobin greater than $7.5 \mathrm{~g} / \mathrm{L}$ (transfusion was permissible), platelets greater than $75 \times 10^{9} / \mathrm{L}$, serum potassium 
greater than or equal to $3.5 \mathrm{mEq} / \mathrm{L}$, and serum magnesium greater than or equal to 1.7 $\mathrm{mg} / \mathrm{dL}$ (supplementation to correct electrolytes was permissible).

Patients were excluded if they had persistent blood pressure of greater than or equal to 160/95; current or history of CNS malignant disease; grade 1 or higher neuralgia if due to peripheral neuropathy of greater than or equal to grade 2 paresthesias, peripheral motor neuropathy, or peripheral sensory neuropathy within 14 days prior to enrollment; clinically significant active infection; or were less than 3 weeks from prior cancer treatment. Other exclusion criteria included risks related to torsades de pointes and heart disease, including heart-related arrhythmias and concomitant treatment with and anti-arrhythmic agents. Patients were excluded from the study if they had an ejection fraction of less than $40 \%$ by MUGA scan or less than $50 \%$ by echocardiogram. Patients with other malignancies and current or ongoing treatment with chemotherapy or investigational agents were also excluded. Patients with CTCL were excluded if they received extracorporeal photopheresis, phototherapy with PUVA, or UV therapy within 2 weeks prior to study treatment; or systemic corticosteroids within 3 weeks of study treatment.

This study was performed after Institutional Review Board approval and in accordance with an assurance filed with and approved by the Department of Health and Human Services.

Informed consent was obtained from each subject before enrollment in the study. This trial is registered at www.clinicaltrials.gov as NCT00963274.

\section{Treatment plan}

This was a phase 1 , non-randomized, dose-escalation study designed to determine the maximum tolerated dose (MTD) for the combination of bortezomib and romidepsin. On days 1,8 , and 15 of a 28 -day cycle, the schedule of administration was intravenous (IV) push bortezomib followed by a 4-hour IV infusion of romidepsin. The starting dose for bortezomib was $1.3 \mathrm{mg} / \mathrm{m}^{2}$ and $8 \mathrm{mg} / \mathrm{m}^{2}$ for romidepsin (Table I). Bortezomib was administered IV because subcutaneous administration had not yet been designated as the standard route of administration at the time the protocol was first written and approved.

Disease status was assessed monthly by physical examinations and blood cell counts; CT imaging (if clinically indicated) was performed every 2 months for the first 6 months, and then every 2 to 3 months; and by bone marrow, as clinically indicated. Patients received full supportive care, tumor lysis prophylaxis per institutional criteria, and prophylactic antiviral treatment. Electrocardiograms were performed prior to each dose of romidepsin and QTc prolongation monitoring was used in this study. Patients were excluded if their QTc interval was greater than or equal to grade 2 according to NCI CTCAE v4.0 (greater than $480 \mathrm{~ms}$ ). Prior to each scheduled administration of romidepsin, QTc interval was calculated from echocardiogram using the Fridericia correction equation. If any cardiac toxicities were present, study drug doses were omitted, modified, or discontinued per protocol. Magnesium and potassium levels were checked and corrected as needed, per protocol criteria, prior to each dose of romidepsin. 


\section{Study design, definition of dose-limiting toxicity, and identification of the MTD}

This study used a $3+3$ dose-escalation design (Table I). Dose level -1 was reserved for use only in the event that dose level 1 exceeded the MTD and was defined as $1 \mathrm{mg} / \mathrm{m}^{2}$ bortezomib and 6 romidepsin $\mathrm{mg} / \mathrm{m}^{2}$; starting dose level 1 was $1.3 \mathrm{mg} / \mathrm{m}^{2}$ bortezomib and 8 romidepsin $\mathrm{mg} / \mathrm{m}^{2}$; followed by dose level $2 \mathrm{~A}$ at $1.3 \mathrm{mg} / \mathrm{m}^{2}$ bortezomib and 10 romidepsin $\mathrm{mg} / \mathrm{m}^{2}$; dose level $2 \mathrm{~B}$ was $1.6 \mathrm{mg} / \mathrm{m}^{2}$ bortezomib and 8 romidepsin $\mathrm{mg} / \mathrm{m}^{2}$; dose level 3 was $16 \mathrm{mg} / \mathrm{m}^{2}$ bortezomib and 10 romidepsin $\mathrm{mg} / \mathrm{m}^{2}$; and dose level 4 was $1.6 \mathrm{mg} / \mathrm{m}^{2}$ bortezomib and 12 romidepsin $\mathrm{mg} / \mathrm{m}^{2}$. For dose level 2, patients were enrolled in alternating sequences to dose levels $2 \mathrm{~A}$ and $2 \mathrm{~B}$ until the relationship to the MTD was determined; if the MTD was not reached at dose level 2, then enrollment would continue to on to dose level 3 followed by dose level 4, as appropriate. Dose levels were expanded to 6 patients if a doselimiting toxicity (DLT) was observed. The MTD was defined as the highest dose level at which fewer than 2 of 6 patients experienced a DLT during the first cycle of therapy. DLT was defined as any of the following related AEs that occurred during cycle 1: (1) any toxicity greater than or equal to grade 3 except neutropenia, leukopenia, lymphopenia, thrombocytopenia, anemia, febrile neutropenia, or hyponatremia; (2) grade 4 neutropenia, or thrombocytopenia lasting 3 or more days or accompanied by bleeding or sepsis (anemia, leukopenia, and lymphopenia were not dose-limiting); (3) inability to administer chemotherapy on 2 of 3 dosing days due to dose modification for toxicity.

\section{Toxicity evaluation}

All AEs were characterized with respect to attribution, severity, and study treatment relatedness and were reported according to the NCI Common Terminology Criteria for Adverse Events version 4.0. AEs were assessed on an ongoing basis during study participation.

\section{Response evaluation}

For CLL, response criteria from the NCI Working Group were used [22]. SLL, PTCL, and indolent B-cell lymphoma patients were evaluated according to the Revised Response Criteria for Malignant Lymphoma [23]. For CTCL, response criteria from the Cutaneous Lymphoma Task Force of the European Organization for Research and Treatment of Cancer were used [24].

\section{Drug supply}

Bortezomib (Velcade; Millennium Pharmaceuticals, Inc., Cambridge, MA) and romidepsin (Istodax, FK228, FR901228, depsipeptide; Celgene Corporation, Summit, NJ) were obtained from the manufacturers.

\section{Correlative study methods}

Triplicate samples of peripheral blood (5 to $6 \mathrm{~mL}$ ) were obtained before (pre-treatment) and 20 to 24 hours after cycle 1 day 1 of study treatment (post-treatment). Samples were collected only from patients with CLL with WBC greater than or equal to 15,000 and 70\% lymphocytes to avoid problems with interpretation due to cellular heterogeneity. Sample collection was optional for patients. PBMC were isolated by Ficoll gradient according to the 
manufacturer's instructions, and protein extraction and Western blot analyses were performed as previously described [25]. Immunoblots were probed with the following primary antibodies: Bcl-XL (Cell Signaling), Bim (Cell Signaling), GAPDH (Sigma), NFkB2 p100/p52 (Cell Signaling), p84 (ThermoFisher Scientific), NFkB p65/RelA (Millipore), tubulin (Sigma), and XIAP (Cell Signaling). Prior to Western blot analysis of RelA, the nuclear fraction was isolated according to Suzuki et al [26]. An Odyssey Imager (LI-COR Biosciences) was used to quantify binding of IRDye 680LT-conjugated secondary antibodies (LI-COR Biosciences).

\section{Statistical analysis}

Descriptive statistics such as frequency, proportion, mean, median, and range were used to summarize patient demographic characteristics, hematologic and non-hematologic AEs by grade, DLTs by dose level, and best clinical response by diagnosis. The small sample size and dose heterogeneity of the study did not permit conclusive statistical analysis of the correlative studies.

\section{Results}

Patients

The characteristics of the 18 patients enrolled in this study are reported in Table II.

\section{Toxicities}

This treatment regimen was generally well tolerated. The most common grade 3 and 4 AEs related to study treatment for all treated patients included grade 3 anemia (11\%), fatigue $(11 \%)$, nausea (11\%), neutropenia (11\%), and vomiting (17\%); and grade 4 neutropenia (17\%) (Table III). Common grade 2 AEs possibly, probably, or definitely related to study treatment included fatigue (50\%), leukopenia (22\%), lymphopenia (22\%), nausea (50\%), neutropenia (39\%), thrombocytopenia (44\%), and vomiting (22\%) (Table III). One patient with PTCL died from progressive disease unrelated to study treatment while on the study.

\section{DLTs and MTD}

Dose levels and DLTs are reported in Table IV. DLTs were determined in cycle 1. There was 1 DLT at dose level 2A (grade 3 fatigue), 2 DLTs at dose level 2B (grade 3 chills [associated with grade 2 cytokine release syndrome] and grade 3 vomiting), and no DLTs at dose level 1 (Tables I and IV). Four patients initiated cycle 1, but they were not evaluable for DLT (3 on dose level $2 \mathrm{~A}$ and 1 on dose level 2B) and were replaced. Two patients received insufficient drug exposure in cycle 1 to be DLT evaluable, 1 was deemed ineligible, and 1 inadvertently received a lower dose of bortezomib during cycle 1 than required by the enrolled dose level. Dose level 2A (bortezomib $1.3 \mathrm{mg} / \mathrm{m}^{2}$, romidepsin $10 \mathrm{mg} / \mathrm{m}^{2}$ ) was identified as the MTD.

\section{Disease response}

Two patients had a partial response (PR; 1 patient remains on treatment), 8 patients had a best response of stable disease $(\mathrm{SD} ; \mathrm{CLL} / \mathrm{SLL}=6 ; \mathrm{CTCL}=1$; indolent $\mathrm{B}$-cell lymphoma $=$ 1), and 8 had progressive disease (PD). One PR occurred in a patient at dose level 2B whose 
CLL was ZAP70 positive and 17p13(p53) deletion negative, and who had previously been treated with 4 lines of chemotherapy. The PR was achieved after 2 cycles, was ongoing after 4 cycles, and the patient proceeded to allogeneic stem cell transplant. The second PR was observed after 6 cycles in a patient with relapsed FL on dose level 2A. This patient remains on treatment (cycle 26) 2 years after beginning treatment, as of the time of this report. The median duration of response for the 8 patients who achieved SD was 3.5 cycles with a range of 1 to 6 cycles.

\section{Correlative studies}

PBMC samples for correlative studies were obtained from 3 of the 18 patients on the study. All 3 patients had CLL/SLL; 2 had a best response of SD (004 and 017) and 1 had a best response of PD (011). Pre- and post-treatment levels of XIAP, Bcl-XL, and Bim, determined by Western blot analysis, showed considerable variation between patients (Figure $1 \mathrm{~A}-\mathrm{C}$ and Supplemental Figure 1). Bcl-XL yielded the most consistent response between patients, with a trend toward diminished expression post-treatment. Changes in expression of XIAP and Bim were variable between patients. Nuclear RelA expression (Figure 1D and Supplemental Figure 2) and total p100 to p52 conversion levels (Figure 1E and Supplemental Figure 3) were also quantified using Western blot analysis. NF- $\mathrm{kB}$ expression was also highly variable. p100 to 552 conversion trended toward a post-treatment decline. The small sample size and dose heterogeneity of the study did not permit conclusive statistical analysis of the correlative studies.

\section{Discussion}

The results of this study demonstrate that the combination of bortezomib and romidepsin can be safely and tolerably administered to patients with CLL/SLL or B- and T-cell lymphoma (Tables II-IV). Overall, the most common grade 3 and 4 AEs (10\% to 20\%) were anemia, neutropenia, fatigue, nausea, and vomiting (Table III). These toxicities are similar to those observed for both bortezomib [27] and romidepsin [10-14] when used as single agents for the treatment of hematologic malignancies. A trial that evaluated the combination of romidepsin, bortezomib, and dexamethasone in multiple myeloma showed a similar, if not greater, toxicity profile of grade 3 and 4 hematologic and non-hematologic AEs compared to the present study [15].

No DLTs were observed at dose level 1 . There was 1 DLT at dose level 2A (grade 3 fatigue) and 2 DLTs at dose level 2B (grade 3 chills and grade 3 vomiting). Accrual to dose levels 2A and 2B took place using an alternating enrollment strategy. Dose level 2A (bortezomib 1.3 $\mathrm{mg} / \mathrm{m}^{2}$, romidepsin $10 \mathrm{mg} / \mathrm{m}^{2}$; Table I) was identified as the MTD (Table IV).

Of the 18 patients enrolled on this study, the majority of patients had CLL/SLL, (13 of 18). All patients with CLL/SLL received prior fludarabine-based regimens. There were 2 objective responses, characterized as PRs (Table V). Both achieved PRs were noteworthy. One PR occurred in a patient with ZAP70-positive CLL who relapsed after 4 lines of chemotherapy. The PR was achieved after 2 cycles and after cycle 4 the patient proceeded to allogeneic stem cell transplant. The second PR was observed after 6 cycles in a patient with relapsed FL after 1 line of therapy. This patient remains on treatment in cycle 26 with an 
ongoing PR. Eight patients had a best response of SD (CLL/SLL $=6$; CTCL $=1$; indolent Bcell lymphoma $=1$ ), and 8 had PD. The median duration of response for the 8 patients who achieved SD was 3.5 cycles.

The response rate for CLL/SLL in the limited number of patients treated in this study was slightly higher than that observed in a phase 1 trial of romidepsin in which there were no objective responses among 20 patients with CLL (10 patients) and AML (10 patients) [28]. Romidepsin has single-agent clinical activity with significant and durable responses in patients with relapsed/refractory CTCL with an overall response rate 34\% [12]. No objective response was achieved in patients with PTCL (2 patients) or CTCL (1 patient) in our study.

Currently, there are no HDACIs approved specifically for the treatment of B-cell lymphoma; however, there are data with select HDACIs that support their use in B-cell malignancies [29-31]. One of the earliest agents to show clinically significant HDACI activity in B-cell lymphoma was valproic acid (Depakote), which induced a CR in a patient with relapsed, transformed FL [32]. In our study, we enrolled 2 patients with indolent lymphoma. The patient with FL achieved an ongoing PR and has been on treatment for 2 years without any significant treatment-related toxicity; this patient currently remains on treatment. The second patient, diagnosed with marginal zone lymphoma, achieved SD and remained on study for 3 cycles. The study was completed before additional patients with indolent lymphoma could be enrolled; however, the responses obtained by the 2 patients with indolent lymphoma suggest that further investigation of this combination in patients with indolent lymphoma may be warranted.

The primary goal of the correlative studies was to test the feasibility of obtaining candidate pharmacodynamic biomarkers for use in future phase 2 trials. Our preclinical studies showed that the combination of bortezomib and romidepsin, administered at very low ( $\sim 3$ to $5 \mathrm{nM}$ ) concentrations, resulted in a striking increase in apoptosis in fresh primary CLL cells, including cells from patients with CLL refractory to standard treatments [19]. This was associated with prevention of HDACI-mediated NF- $\kappa B$ activation and downregulation of the canonical NF- $\mathrm{kB}$ pathway. Correlative studies examining the pre- and post-treatment expression of XIAP, Bcl-XL, Bim, NF- $\mathrm{BB}$ RelA, and p100 to 552 processing were performed using samples from 3 patients with CLL/SLL: 004 (SD), 011 (PD), and 017 (SD). The small sample size and limited responses did not allow correlations to be made between protein expression of these markers and treatment outcome. However, the data obtained from these samples suggest that the methods used are feasible for inclusion in subsequent phase 2 trials.

In summary, an MTD was reached for the combination of bortezomib and romidepsin in the treatment of patients with CLL and B- and T-cell lymphoma. Among 18 heavily pre-treated patients, there were 2 PRs, 8 SDs, and 8 PDs. The small sample size and high variability in the correlative data prevent definitive conclusions to be drawn regarding the effects of combined treatment with bortezomib and romidepsin on either the canonical or alternative NF- $\kappa B$ pathways in this patient population. However, the ability to obtain quantifiable data from this subset of patients does support the feasibility of the correlative methodology and its application to future studies. Overall, the combination of bortezomib and romidepsin in 
patients with relapsed CLL/SLL or B-cell or T-cell lymphoma refractory to multiple lines of therapy resulted in modest responses. Although the present results do not unequivocally support a phase 2 clinical trial in relapsed/refractory NHL, at least with the current schedule, the possibility remains of exploring alternative schema and combinations with new agents including proteasome inhibitors such as carfilzomib or ixazomib or HDACIs such as belinostat, particularly in patients with indolent NHL.

\section{Supplementary Material}

Refer to Web version on PubMed Central for supplementary material.

\section{Acknowledgments}

The authors thank Elizabeth Stoddert Collins, MA, CCRP for assistance with data acquisition.

This study was supported by grants from the National Institutes of Health (NCI R21 CA137823, NCI P30 CA016059 [Cancer Center Support Grant to Massey Cancer Center], and NCRR M01-RR00065 [Clinical Research Center Grant to Virginia Commonwealth University]).

\section{References}

1. Shankland KR, Armitage JO, Hancock BW. Non-Hodgkin lymphoma. Lancet. 2012; 380:848-857. [PubMed: 22835603]

2. Howlader, N., Noone, AM., Krapcho, M., et al. SEER Cancer Statistics Review 1975-2010. National Cancer Institute; 2013 September 9, 2013. <http://seer.cancer.gov/csr/1975_2010/> [Accessed 2013 September 9, 2013]

3. Thompson PA, Wierda WG. Eliminating minimal residual disease as a therapeutic end point: working toward cure for patients with CLL. Blood. 2016; 127:279-286. [PubMed: 26576865]

4. Buac D, Shen M, Schmitt S, et al. From bortezomib to other inhibitors of the proteasome and beyond. Curr Pharm Des. 2013; 19:4025-4038. [PubMed: 23181572]

5. Orlowski RZ, Stinchcombe TE, Mitchell BS, et al. Phase I trial of the proteasome inhibitor PS-341 in patients with refractory hematologic malignancies. J Clin Oncol. 2002; 20:4420-4427. [PubMed: 12431963]

6. Jia L, Gopinathan G, Sukumar JT, Gribben JG. Blocking autophagy prevents bortezomib-induced NF-kappaB activation by reducing I-kappaBalpha degradation in lymphoma cells. PLoS One. 2012; 7:e32584. [PubMed: 22393418]

7. Fisher RI, Bernstein SH, Kahl BS, et al. Multicenter phase II study of bortezomib in patients with relapsed or refractory mantle cell lymphoma. J Clin Oncol. 2006; 24:4867-4874. [PubMed: 17001068]

8. Bose P, Batalo MS, Holkova B, Grant S. Bortezomib for the treatment of non-Hodgkin's lymphoma. Expert Opin Pharmacother. 2014; 15:2443-2459. [PubMed: 25263936]

9. Piekarz RL, Bates SE. Epigenetic modifiers: basic understanding and clinical development. Clin Cancer Res. 2009; 15:3918-3926. [PubMed: 19509169]

10. Piekarz RL, Frye R, Prince HM, et al. Phase 2 trial of romidepsin in patients with peripheral T-cell lymphoma. Blood. 2011; 117:5827-5834. [PubMed: 21355097]

11. Yazbeck VY, Grant S. Romidepsin for the treatment of non-Hodgkin's lymphoma. Expert Opin Investig Drugs. 2015; 24:965-979.

12. Piekarz RL, Frye R, Turner M, et al. Phase II multi-institutional trial of the histone deacetylase inhibitor romidepsin as monotherapy for patients with cutaneous T-cell lymphoma. J Clin Oncol. 2009; 27:5410-5417. [PubMed: 19826128]

13. Whittaker SJ, Demierre MF, Kim EJ, et al. Final results from a multicenter, international, pivotal study of romidepsin in refractory cutaneous T-cell lymphoma. J Clin Oncol. 2010; 28:4485-4491. [PubMed: 20697094] 
14. Coiffier B, Pro B, Prince HM, et al. Results from a pivotal, open-label, phase II study of romidepsin in relapsed or refractory peripheral T-cell lymphoma after prior systemic therapy. $\mathrm{J}$ Clin Oncol. 2012; 30:631-636. [PubMed: 22271479]

15. Harrison SJ, Quach H, Link E, et al. A high rate of durable responses with romidepsin, bortezomib, and dexamethasone in relapsed or refractory multiple myeloma. Blood. 2011; 118:6274-6283. [PubMed: 21911830]

16. Yu C, Rahmani M, Conrad D, Subler M, Dent P, Grant S. The proteasome inhibitor bortezomib interacts synergistically with histone deacetylase inhibitors to induce apoptosis in Bcr/Abl+ cells sensitive and resistant to STI571. Blood. 2003; 102:3765-3774. [PubMed: 12893773]

17. Catley L, Weisberg E, Kiziltepe T, et al. Aggresome induction by proteasome inhibitor bortezomib and alpha-tubulin hyperacetylation by tubulin deacetylase (TDAC) inhibitor LBH589 are synergistic in myeloma cells. Blood. 2006; 108:3441-3449. [PubMed: 16728695]

18. Hideshima T, Richardson PG, Anderson KC. Mechanism of action of proteasome inhibitors and deacetylase inhibitors and the biological basis of synergy in multiple myeloma. Mol Cancer Ther. 2011; 10:2034-2042. [PubMed: 22072815]

19. Dai Y, Chen S, Kramer LB, Funk VL, Dent P, Grant S. Interactions between bortezomib and romidepsin and belinostat in chronic lymphocytic leukemia cells. Clin Cancer Res. 2008; 14:549_ 558. [PubMed: 18223231]

20. Zinzani PL, Musuraca G, Tani M, et al. Phase II trial of proteasome inhibitor bortezomib in patients with relapsed or refractory cutaneous T-cell lymphoma. J Clin Oncol. 2007; 25:42934297. [PubMed: 17709797]

21. O'Connor OA, Wright J, Moskowitz C, et al. Phase II clinical experience with the novel proteasome inhibitor bortezomib in patients with indolent non-Hodgkin's lymphoma and mantle cell lymphoma. J Clin Oncol. 2005; 23:676-684. [PubMed: 15613699]

22. Hallek M, Cheson BD, Catovsky D, et al. Guidelines for the diagnosis and treatment of chronic lymphocytic leukemia: a report from the International Workshop on Chronic Lymphocytic Leukemia updating the National Cancer Institute-Working Group 1996 guidelines. Blood. 2008; 111:5446-5456. [PubMed: 18216293]

23. Cheson BD, Pfistner B, Juweid ME, et al. Revised response criteria for malignant lymphoma. J Clin Oncol. 2007; 25:579-586. [PubMed: 17242396]

24. Olsen EA, Whittaker S, Kim YH, et al. Clinical end points and response criteria in mycosis fungoides and Sezary syndrome: a consensus statement of the International Society for Cutaneous Lymphomas, the United States Cutaneous Lymphoma Consortium, and the Cutaneous Lymphoma Task Force of the European Organisation for Research and Treatment of Cancer. J Clin Oncol. 2011; 29:2598-2607. [PubMed: 21576639]

25. Holkova B, Kmieciak M, Perkins EB, et al. Phase I trial of bortezomib (PS-341; NSC 681239) and "nonhybrid" (bolus) infusion schedule of alvocidib (flavopiridol; NSC 649890) in patients with recurrent or refractory indolent B-cell neoplasms. Clin Cancer Res. 2014; 20:5652-5662. [PubMed: 25248382]

26. Suzuki K, Bose P, Leong-Quong RY, Fujita DJ, Riabowol K. REAP: A two minute cell fractionation method. BMC Res Notes. 2010; 3:294. [PubMed: 21067583]

27. Alsina M, Trudel S, Furman RR, et al. A phase I single-agent study of twice-weekly consecutiveday dosing of the proteasome inhibitor carfilzomib in patients with relapsed or refractory multiple myeloma or lymphoma. Clin Cancer Res. 2012; 18:4830-4840. [PubMed: 22761464]

28. Byrd JC, Marcucci G, Parthun MR, et al. A phase 1 and pharmacodynamic study of depsipeptide (FK228) in chronic lymphocytic leukemia and acute myeloid leukemia. Blood. 2005; 105:959967. [PubMed: 15466934]

29. Kelly WK, Richon VM, O'Connor O, et al. Phase I clinical trial of histone deacetylase inhibitor: suberoylanilide hydroxamic acid administered intravenously. Clin Cancer Res. 2003; 9:35783588. [PubMed: 14506144]

30. O'Connor OA, Heaney ML, Schwartz L, et al. Clinical experience with intravenous and oral formulations of the novel histone deacetylase inhibitor suberoylanilide hydroxamic acid in patients with advanced hematologic malignancies. J Clin Oncol. 2006; 24:166-173. [PubMed: 16330674] 
31. Watanabe T, Kato H, Kobayashi Y, et al. Potential efficacy of the oral histone deacetylase inhibitor vorinostat in a phase I trial in follicular and mantle cell lymphoma. Cancer Sci. 2010; 101:196200. [PubMed: 19817748]

32. Zain J, Rotter A, Weiss L, Forman S, Kirschbaum MH. Valproic acid monotherapy leads to CR in a patient with refractory diffuse large B cell lymphoma. Leuk Lymphoma. 2007; 48:1216-1218.

[PubMed: 17577787] 
A

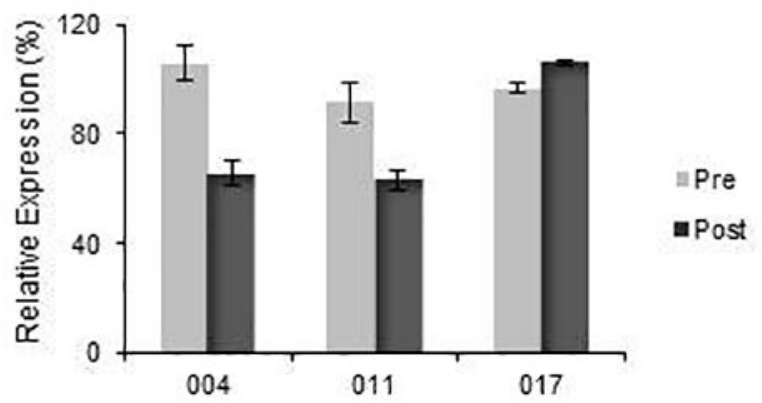

C

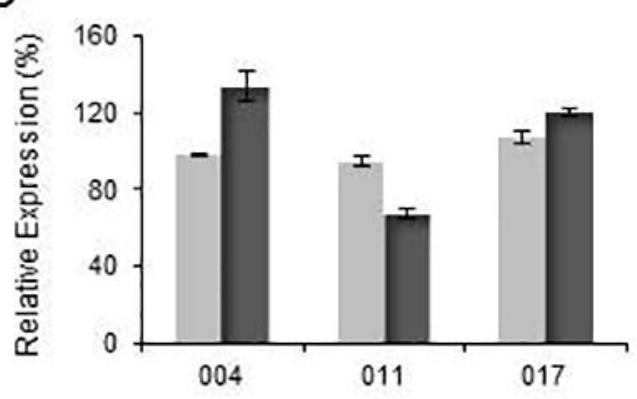

$\approx$ Pre

a Post
B

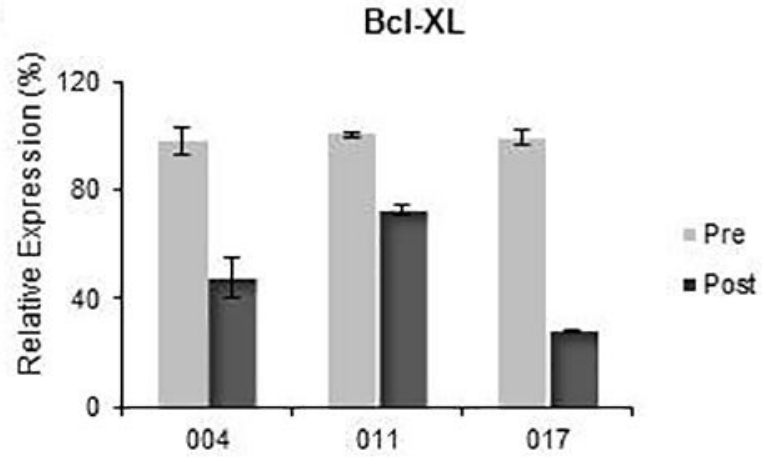

D

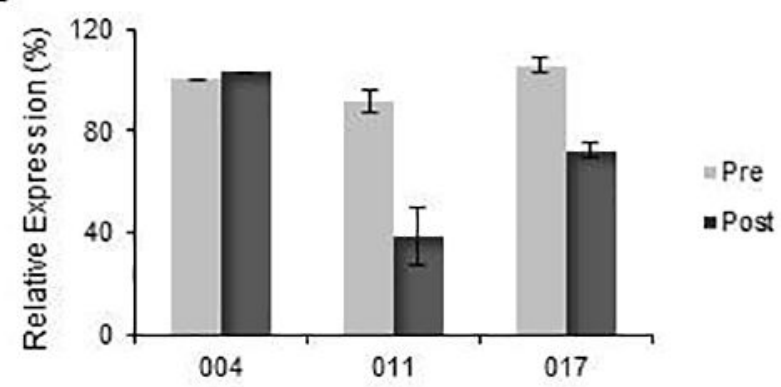

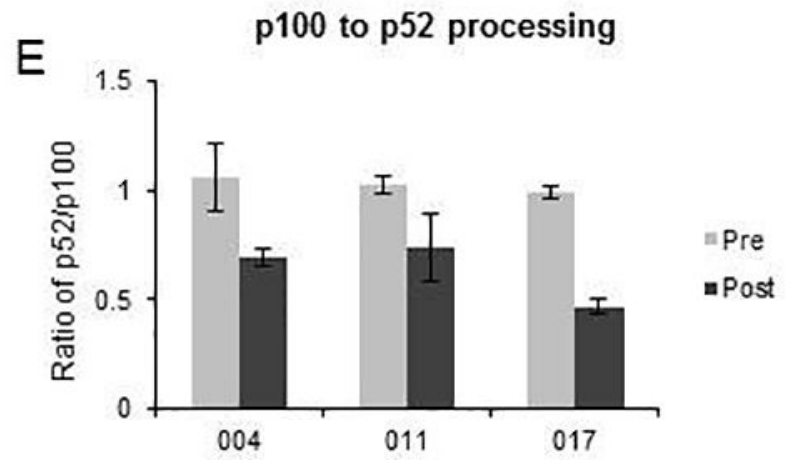

Fig. 1.

Pharmacodynamic analysis of pre- and post-treatment blood samples. Relative expression levels of total XIAP, Bcl-XL, Bim (A-C), and nuclear RelA (D) in PBMC from 3 patients were measured by Western blot analysis. Samples were obtained prior to the first dose of study treatment (pre-treatment) and 20 to 24 hours following the first dose of study treatment (post-treatment). Biomarker expression levels were normalized to GAPDH and the normalized pre-treatment value for each sample was defined as $100 \%$. E) p100 to p50 processing pre- and post-treatment is shown as the ratio of p52 to p100 expression, as determined by Western blot. The pre-treatment samples were normalized to 1 prior to calculation of the p100/p52 ratio. All samples were run in triplicate and data are shown as the mean $\pm \mathrm{SD}$. 


\section{Table I}

Dose level escalation schema.

\begin{tabular}{ccc}
\hline $\begin{array}{c}\text { Dose } \\
\text { level }\end{array}$ & \multicolumn{2}{c}{ Doses } \\
\hline-1 & 1.0 & 6 \\
1 & 1.3 & 8 \\
$2 \mathrm{~A}$ & 1.3 & 10 \\
$2 \mathrm{~B}$ & 1.6 & 8 \\
3 & 1.6 & 10 \\
4 & 1.6 & 12 \\
\hline
\end{tabular}

For all dose levels, patients were enrolled in cohorts of 3. For dose level 2, patients were enrolled in an alternating sequence to dose levels $2 \mathrm{~A}$ and 2B until the relationship to the MTD had been determined. If no MTD was reached at dose level 2, then enrollment would have continued with dose escalation to dose level 3, followed by dose level 4, as outlined. Dose levels 3 and 4 were not explored in this study because the MTD was reached at dose level $2 \mathrm{~A}$. 


\section{Table II}

Patient enrollment and characteristics.

\begin{tabular}{|c|c|}
\hline Gender & No. of patients \\
\hline Female & 3 \\
\hline Male & 15 \\
\hline Total & 18 \\
\hline Race & No. of patients \\
\hline Black or African American & 5 \\
\hline White & 13 \\
\hline Ethnicity & No. of patients \\
\hline Hispanic or Latino & 1 \\
\hline Non-Hispanic & 17 \\
\hline Age range & Years \\
\hline Median & 56.5 \\
\hline Range & $31-76$ \\
\hline Performance status & No. of patients \\
\hline 0 & 4 \\
\hline 1 & 14 \\
\hline Diagnosis & No. of patients \\
\hline CLL/SLL & 13 \\
\hline CTCL & 1 \\
\hline Indolent B-cell lymphoma & 2 \\
\hline Follicular lymphoma & 1 \\
\hline Marginal zone B-cell lymphoma & 1 \\
\hline PTCL & 2 \\
\hline Anaplastic large cell lymphoma, ALK-negative & 1 \\
\hline PTCL, not otherwise specified & 1 \\
\hline Prior treatment & No. of patients \\
\hline Autologous stem cell transplantation & 1 \\
\hline Radiation & 2 \\
\hline Chemotherapy & No. of regimens \\
\hline Median & 3 \\
\hline Range & $1-6$ \\
\hline Study treatment & No. of cycles \\
\hline Median & 3 \\
\hline Range & $1-26$ \\
\hline
\end{tabular}




\section{Table III}

Grade 2, 3, and 4 hematologic and non-hematologic toxicities occurring during any treatment course and deemed possibly, probably, or definitely related to the study treatment.

\begin{tabular}{|c|c|c|c|}
\hline & \multicolumn{3}{|c|}{ No. of events, No. of patients ( $\%$ of patients) } \\
\hline & Grade 2 & Grade 3 & Grade 4 \\
\hline \multicolumn{4}{|l|}{ Hematologic toxicities } \\
\hline Anemia & $3,2(11)$ & $2,2(11)$ & \\
\hline Lymphocyte count decreased & $8,4(22)$ & $2,1(6)$ & \\
\hline Neutrophil count decreased & $16,7(39)$ & $2,2(11)$ & $3,3(17)$ \\
\hline Platelet count decreased & $17,8(44)$ & & \\
\hline White blood cell decreased & $6,4(22)$ & $2,1(6)$ & \\
\hline \multicolumn{4}{|l|}{ Non-hematologic toxicities } \\
\hline Anorexia & $2,2(11)$ & & \\
\hline Arthralgia & $1,1(6)$ & & \\
\hline Chills & & $1,1(6)$ & \\
\hline Cough & $2,2(11)$ & & \\
\hline Creatinine increased & $2,1(6)$ & & \\
\hline Cytokine release syndrome & $1,1(6)$ & $1,1(6)$ & \\
\hline Dehydration & $1,1(6)$ & & \\
\hline Diarrhea & $1,1(6)$ & $1,1(6)$ & \\
\hline Dizziness & $1,1(6)$ & & \\
\hline Dry eye & $1,1(6)$ & & \\
\hline Dry skin & $1,1(6)$ & & \\
\hline Dyspepsia & $2,2(11)$ & & \\
\hline Ear pain & $1,1(6)$ & & \\
\hline Electrocardiogram QT corrected interval prolonged & $1,1(6)$ & & \\
\hline Esophageal infection & $1,1(6)$ & & \\
\hline Eye disorders, other ${ }^{* \dagger}$ & $2,2(11)$ & $1,1(6)$ & \\
\hline Fatigue & $12,9(50)$ & $2,2(11)$ & \\
\hline Fever & $1,1(6)$ & & \\
\hline Flatulence & $1,1(6)$ & & \\
\hline General disorders, other ${ }^{t}$ & $1,1(6)$ & & \\
\hline Hypophosphatemia & $3,3(17)$ & & \\
\hline Infusion site extravasation & $1,1(6)$ & & \\
\hline Injection site reaction & $2,2(11)$ & & \\
\hline Malaise & $1,1(6)$ & & \\
\hline Myalgia & $2,2(11)$ & & \\
\hline Nausea & $15,9(50)$ & $2,2(11)$ & \\
\hline Oral dysesthesia & $1,1(6)$ & & \\
\hline Peripheral sensory neuropathy & $2,2(11)$ & & \\
\hline Photophobia & $1,1(6)$ & & \\
\hline
\end{tabular}




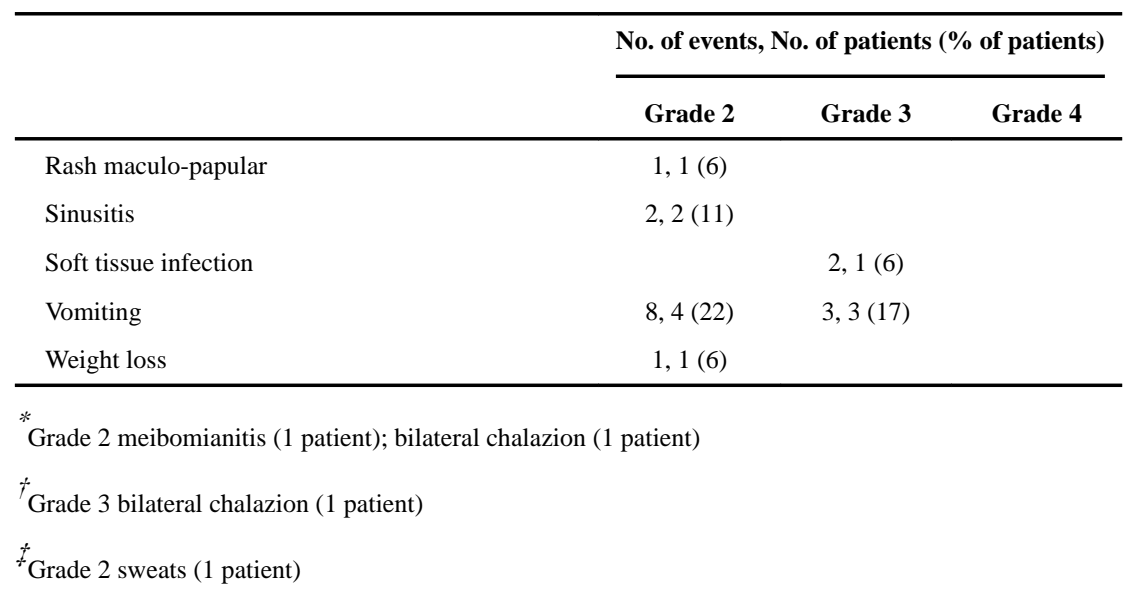



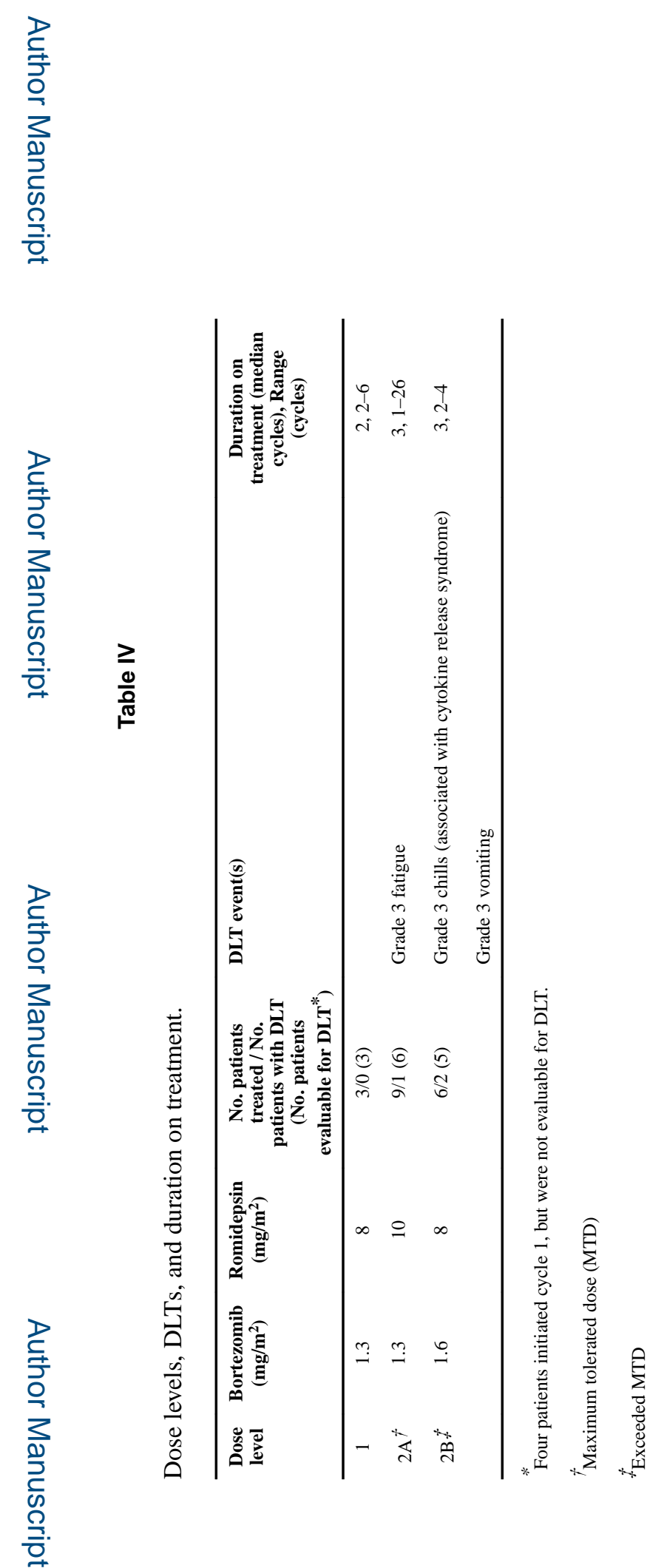

Leuk Lymphoma. Author manuscript; available in PMC 2018 June 01. 
Table V

Response data by diagnosis.

\begin{tabular}{lr}
\hline Best response & No. of patients \\
\hline Complete response (CR) & 0 \\
Partial response (PR) & 2 \\
CLL/SLL & 1 \\
Indolent B-cell lymphoma (FL) & 1 \\
Stable disease (SD) & 8 \\
CLL/SLL & 6 \\
CTCL & 1 \\
Indolent B-cell lymphoma (marginal zone B-cell lymphoma) & 1 \\
Progressive disease (PD) & 8 \\
CLL/SLL & 6 \\
PTCL & 2 \\
\hline
\end{tabular}

